\title{
Intellectual and Psychological Performance in Males Born Small for Gestational Age With and Without Catch-Up Growth
}

\author{
ESTER MARIA LUNDGREN, SVEN CNATTINGIUS, BJÖRN JONSSON, AND TORSTEN TUVEMO \\ Department of Women's and Children's Health, Uppsala University, Uppsala, Sweden [E.M.L., T.T.]; and \\ Departments of Medical Epidemiology [S.C.] and Women's and Children's Health [B.J.], Karolinska
}

Institute, Stockholm, Sweden

\begin{abstract}
Infants born small for gestational age (SGA) have an increased risk of neurologic and intellectual dysfunction. Most of these infants catch up in growth and attain normal height, although some do not. Whether catch-up growth influences intellectual function is not known. To analyze whether intellectual and psychological performance of males in early adulthood are associated with body size at birth or by catch-up growth in height among boys, a population-based cohort was studied. This cohort included all male singletons born without congenital malformations in Sweden from 1973 to 1978 and alive at 18 y ( $n$ $=276,033)$. Information from the Swedish Birth Register was individually linked to the Swedish Conscript Register. Of 254,426 conscripted males, information on intellectual and psychological performance was available for $97 \%$ and $91 \%$, respectively. Low birth weight, short birth length, small head circumference at birth, and preterm birth increased the risk of subnormal
\end{abstract}

\section{ABSTRACT}

intellectual and psychological performance. Among SGA-born males, the most important predictor was the absence of catch-up growth. Being born SGA is associated with increased risk of subnormal intellectual and psychological performance. The data strongly support the view that, for males born SGA, it is an advantage to have catch-up growth in length. (Pediatr Res 50: 91-96, 2001)

CI, confidence interval
IP, intellectual performance
OR, odds ratio
PP, psychological performance
SDS, SD score(s)
SGA, small for gestational age

Several studies indicate that infants born SGA have a higher risk of minimal neurologic dysfunction later in life, reduced mental development potential, and increased risk of subnormal intellectual and psychological performance compared with infants born appropriate for gestational age (1-9). In these studies, SGA was defined based on low birth weight for gestational age.

Growth in children and height in adults are often used as indicators of nutrition and well being (10-12). A positive correlation between height and intelligence has generally been reported $(13,14)$. In a study of young Danish men, intelligence test scores were above the mean among tall men but below in short men (15). We have recently demonstrated that apparently healthy short young men had lower intellectual performance compared with taller men, and that the mean intelligence test score generally increased with height (16).

Received September 25, 2000; accepted February 12, 2001

Correspondence: Torsten Tuvemo, Ph.D., Department of Women's and Children's Health, Section of Pediatrics, Uppsala University Hospital, SE-751 85 Uppsala, Sweden; e-mail: Torsten.Tuvemo@kbh.uu.se

Supported, in part, by Pharmacia Corporation.
Infants born short for gestational age have an increased risk of short adult stature (17-19). Data from Barker's group indicate that being small at birth is a threat to cardiovascular health, especially if obese in adulthood. The question has therefore been raised if catch-up growth in SGA children is a risk rather than an advantage (20). Lack of linear catch-up growth, however, could be a sign of severe growth restriction and brain affections.

The aim of this study was to analyze whether body size at birth among males is associated with subsequent IP and PP, and whether catch-up growth in height in boys born SGA is associated with IP or PP in early adulthood.

\section{METHODS}

The Swedish Birth Register, held by the National Board of Health and Welfare, was started in 1973 and contains data on $>99 \%$ of all births in Sweden (21). The registry includes data on maternal demographics, reproductive history, and complications during pregnancy, delivery, and the neonatal period. All births and deaths are validated every year against another 
central population register, using the mothers' and the infants' unique personal identification numbers, assigned to each Swedish resident at birth.

The Swedish Conscript Register includes information about Swedish males conscripted for military service. Conscription is mandatory and enforced by law. Most men are conscripted at $18-25 \mathrm{y}$ of age. Those with known severe handicaps, congenital malformations, or chronic diseases are not conscripted (about 2.4\% in each birth cohort).

The studied cohort. The Swedish Birth Register comprised information on 312,159 liveborn male infants in the period from 1973 to 1978 . To increase the homogeneity of the study population, we excluded multiple births, congenital malformations, and infants born to non-Nordic mothers. In all, we included 279,435 males, of whom 3,402 died before 18 y of age. The remaining 276,033 males constitute the study population, of whom 21,607 (7.8\%) were not conscripted between January 1991 and January 1997. Of 254,426 conscripted males, data on IP and PP were available in 248,051 (97\%) and 230,988 (91\%) males, respectively.

Information about birth weight, birth length, and head circumference was obtained from the Swedish Birth Register. Gestational age was estimated from the date of the last menstrual period and stratified into very preterm $(\leq 31 \mathrm{wk})$, moderately preterm $(32-36 \mathrm{wk})$, term $(37-41 \mathrm{wk})$, and post-term ( $\geq 42 \mathrm{wk}$ ) births. Birth weight and length were analyzed both as continuous and categorical variables with similar results.
The results are presented using categorical variables to simplify the presentation. Birth weight for gestational age was divided into three categories: light for gestational age, defined as $>2$ SDS below mean birth weight for gestational age; appropriate weight for gestational age, defined as birth weight between -2 and +2 SDS; and heavy for gestational age, defined as birth weight $>2$ SDS above the mean. Birth length for gestational age and head circumference were defined analogously (22). SGA was defined as less than -2 SDS in either birth length or weight for gestational age, and divided into three different subgroups: born short only, born light only, and born both short and light for gestational age. The cutoff at -2 SDS is commonly used to define small size for gestational age. Children shorter than -2 SDS are also those in whom investigation for growth hormone deficiency may be considered. Linear catch-up growth was defined as being born SGA and being above -2 SDS in height at conscription.

Dependent variables. At conscription, all the men undergo a thorough health examination, including height and weight measurements, and a number of tests. The information is computerized and the personal identification number of each subject ensures individual record linkage to other information sources. General IP is measured by a time-limited test package including four dimensions: logical/inductive, verbal, spatial, and theoretical/technical. The test questionnaire contains 160 items, 40 from each dimension, and has been computerized since 1994 (16). The direct interaction with computerized test

Table 1. Mean stanine score for IP and OR and 95\% CI of subnormal performance related to birth characteristics*

\begin{tabular}{|c|c|c|c|c|}
\hline & \multirow[b]{2}{*}{ No. } & \multirow[b]{2}{*}{ Mean (SD) } & \multicolumn{2}{|c|}{ OR $(95 \% \mathrm{CI})$} \\
\hline & & & Crude & Adjusted $\dagger$ \\
\hline \multicolumn{5}{|c|}{ Birth length for gestational age } \\
\hline-2 to $<+2$ SDS & 231,750 & $5.11(1.91)$ & 1.00 & 1.00 \\
\hline$>2$ SDS & 8,363 & $5.17(1.91)$ & $0.93(0.88-0.99)$ & $0.98(0.92-1.05)$ \\
\hline Missing & 1,824 & $4.81(1.95)$ & & \\
\hline-2 to +2 SDS & 233,531 & $5.11(1.91)$ & 1.00 & 1.00 \\
\hline$>2$ SDS & 6,785 & $5.14(1.93)$ & $1.02(0.96-1.08)$ & $1.09(1.01-1.17)$ \\
\hline Missing & 1,295 & $4.80(1.95)$ & & \\
\hline \multicolumn{5}{|l|}{ Head circumference } \\
\hline$<-2 \operatorname{SDS}$ & 7,425 & $4.77(1.95)$ & $1.45(1.40-1.50)$ & $1.28(1.21-1.36)$ \\
\hline-2 to +2 SDS & 231,078 & $5.10(1.91)$ & 1.00 & 1.00 \\
\hline $37-41$ & 209,273 & $5.11(1.91)$ & 1.00 & 1.00 \\
\hline$\geq 42$ & 27,075 & $5.06(1.92)$ & $1.04(1.01-1.08)$ & $1.03(1-1.07)$ \\
\hline Missing & 1,082 & $4.79(1.93)$ & & \\
\hline \multicolumn{5}{|c|}{ Height at conscription } \\
\hline$<-2 \operatorname{SDS} \S$ & 4,700 & $4.38(1.96)$ & $2.05(1.99-2.11)$ & $1.88(1.76-2.01)$ \\
\hline-2 to +2 SDS & 234,294 & $5.11(1.90)$ & 1.00 & 1.00 \\
\hline$>2$ SDS & 6,400 & $5.49(1.88)$ & $0.68(0.61-0.75)$ & $0.70(0.65-0.75)$ \\
\hline Missing & 2,657 & $4.13(2.14)$ & & \\
\hline
\end{tabular}

* Subnormal performance defined as stanine score 0-3.

$\uparrow$ Adjusted for all other variables included in the table using logistic regression.

$\ddagger-2$ SDS corresponds to the following values at 40 completed weeks: birth length $47.0 \mathrm{~cm}$, birth weight $2741 \mathrm{~g}$, head circumference $32.2 \mathrm{~cm}$.

$\S-2$ SDS corresponds to height of $166.0 \mathrm{~cm}$ at conscription. 
Table 2. Mean stanine score for PP and OR and 95\% CI of subnormal performance related to birth characteristics*

\begin{tabular}{|c|c|c|c|c|}
\hline & \multirow[b]{2}{*}{ No. } & \multirow[b]{2}{*}{ Mean (SD) } & \multicolumn{2}{|c|}{ OR $(95 \% \mathrm{CI})$} \\
\hline & & & Crude & Adjusted $\dagger$ \\
\hline \multicolumn{5}{|c|}{ Birth length for gestational age } \\
\hline-2 to +2 SDS & 215,894 & $5.07(1.78)$ & 1.00 & 1.00 \\
\hline$>2$ SDS & 7,792 & $5.11(1.8)$ & $1.01(0.94-1.07)$ & $1.04(0.98-1.11)$ \\
\hline Missing & 1,714 & $4.83(1.84)$ & & \\
\hline-2 to $+2 \operatorname{SDS}$ & 217,531 & $5.07(1.78)$ & 1.00 & 1.00 \\
\hline$>2$ SDS & 6,338 & $5.09(1.80)$ & $0.93(0.86-1.01)$ & $1.00(0.93-1.07)$ \\
\hline Missing & 1,229 & $4.78(1.86)$ & & \\
\hline \multicolumn{5}{|l|}{ Head size } \\
\hline$<-2$ SDS & 6,873 & $4.86(1.77)$ & $1.22(1.15-1.28)$ & $1.11(1.04-1.18)$ \\
\hline-2 to +2 SDS & 215,203 & $5.07(1.78)$ & 1.00 & 1.00 \\
\hline $37-41$ & 195,003 & $5.08(1.78)$ & 1.00 & 1.00 \\
\hline$\geq 42$ & 25,144 & $5.02(1.80)$ & $1.09(1.05-1.12)$ & $1.08(1.04-1.11)$ \\
\hline Missing & 1,025 & $4.80(1.86)$ & & \\
\hline \multicolumn{5}{|c|}{ Height at conscription } \\
\hline$<-2$ SDS & 4,215 & $4.42(1.75)$ & $1.82(1.74-1.90)$ & $1.78(1.66-1.90)$ \\
\hline-2 to +2 SDS & 219,432 & $5.08(1.77)$ & 1.00 & 1.00 \\
\hline$>2$ SDS & 6,036 & $5.36(1.76)$ & $0.76(0.68-0.84)$ & $0.76(0.71-0.82)$ \\
\hline Missing & 1,305 & $2.07(1.41)$ & & \\
\hline
\end{tabular}

* Subnormal performance defined as stanine score $0-3$.

$\dagger$ Adjusted for all other variables included in the table using logistic regression.

programs avoids the risk for observer bias to, for example, short people. PP during mental stress is also evaluated. The evaluation is performed using semistructured interviews by specialized psychologists with the aim of measuring how the conscript might be able to manage difficult situations during stress. The results are acknowledged to reflect different aspects of personality. The results on IP and PP are presented as standard nine (stanine) scores (mean $=5, \mathrm{SD}=2$ ). Subnormal performance was defined as a score of $\leq 3$ (i.e. less than -1 $\mathrm{SD})$. The $10 \%$ scoring $\leq 2$ in IP can be expected to have difficulties in ordinary basic education programs, and the $20 \%$ scoring $\leq 3$ cannot be expected to be successful in higher education.

Statistical methods. Analyses were performed using bivariate and multiple logistic and linear regression analyses. OR are presented with $95 \%$ CI within parentheses. The standard statistical package SPSS for Windows (version 10.0, SPSS, Chicago, IL, U.S.A.) was used in the statistical calculations.

The study was approved by the Ethics Committee of the Medical Faculty of Uppsala University.

\section{RESULTS}

In the analyzed cohort of conscripted young men, $0.3 \%$ were born very preterm $(\leq 31 \mathrm{wk})$, and $4.0 \%$ were born moderately preterm (32-36 wk). In all, 2.6\% were born light for gestational age, and $2.5 \%$ were short for gestational age. In relation to the reference population (22), there was a slightly increased number of newborns above +2 SDS in birth length and weight (3.4\% and $2.7 \%$, respectively).
Males born below -2 SDS in length for gestational age had a lower mean IP score than those born above -2 SDS, and similar patterns were seen when analyzing birth weight and head circumference (Table 1). Males born preterm, especially those born very preterm, had lower mean IP scores than those born at term or post-term. Mean IP consistently increased with height at conscription. Compared with those born with normal birth characteristics, those born short, light, or with small head circumference had increased risks of subnormal IP. The highest increased risk, though, was among those born very preterm compared with those born term, and among those who were short at conscription compared with those with a normal adult height. In the multivariate analyses, these risks were slightly attenuated, but remained significantly increased.

The correlation coefficient between the two outcome variables, IP and PP, was 0.36, and similar patterns as in IP were seen in PP. Males born with birth length, birth weight, and head circumference below -2 SDS had lower mean scores in PP than males with normal birth characteristics. Moreover, as in IP, mean PP increased with gestational age and adult stature. In bivariate analyses, men born short, light, or with small head circumferences were at increased risk of subnormal PP compared with men with normal birth size. The risk of subnormal PP was also increased among men born preterm compared with men born at term, and among men who were short at conscription compared with those with a normal adult stature (Table 2). These risks remained significantly increased in the multivariate analysis, even though they were slightly attenuated. When the multivariate analyses were repeated after excluding adult stat- 
ure as an independent predictor, the association between birth characteristics and low IP or PP remained essentially unchanged (data not shown). We also repeated the analyses after defining a subnormal IP and PP as scores $\leq 2$ or $\leq 4$, respectively, with minor changes in results (data not shown).

In the evaluation of the effect of catch-up growth on IP and $\mathrm{PP}$, the analyses were restricted to the different subgroups of males born SGA. The distributions of stanine scores for IP are shown in Figure 1. Among men born SGA, low mean scores in IP were consistently more common among those without catch-up growth than those with catch-up growth.

The highest mean score among males born SGA in IP was seen in the subgroup born short with a normal adult height, and the lowest score was obtained in the group born both short and light and still short at conscription (Table 3). Compared with males born short having a normal adult height, the males in the

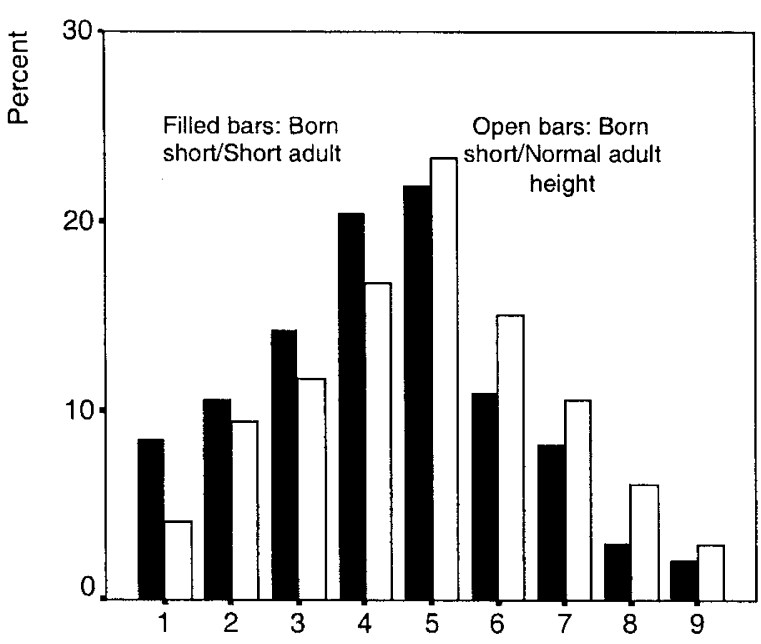

a

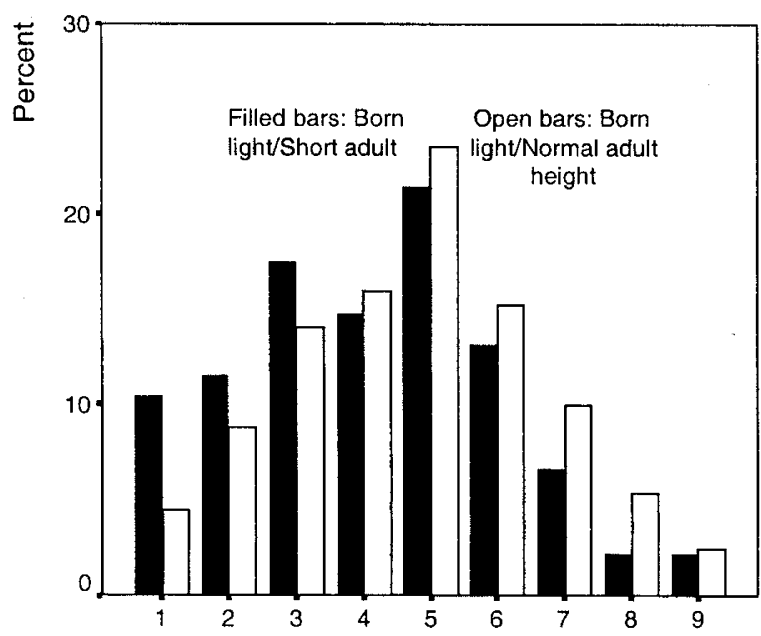

b

Figure 1. Distribution of IP scores in males born short $(A)$ or light $(B)$ for gestational age with adult height below or above -2 SDS.
SGA groups who were short at conscription had an increased risk of a subnormal score. Compared with males being only short or only light at birth, the risk of subnormal IP was slightly increased among males being both short and light at birth.

Catch-up growth was also associated with increased mean score of PP during stress in all SGA subgroups. Men born short and light, who also were short at conscription, had the overall lowest result. Among men without catch-up growth, those born short had a better psychological score than those born light. As in the case of IP, there was an increased risk of subnormal PP in males of all SGA subgroups if they were short at conscription, compared with males born short and having had catch-up growth (Table 3). The patterns of distribution of stanine scores were similar to corresponding distributions for IP.

SGA boys born both short and light had not only lower IP and PP scores than other SGA infants, but also lower mean birth weight than SGA infants born light only, and a shorter birth length than SGA infants born short only (Table 4). We therefore investigated whether the differences in test results between SGA groups were explained by differences in birth weight and length. This question was investigated by introducing birth length, birth weight, and an interaction term, birth weight $\times$ birth length, as predictors of IP and PP in the multivariate regression models. Birth weight and length remained significant predictors in the models, but the interaction term was not statistically significant $(p>0.05)$. Rates of subnormal IP/PP among those born short and light were consistent with expected rates on those born short only and those born light only (assuming a multiplicative model).

\section{DISCUSSION}

The results of this study show that males born SGA with catch-up growth and thus obtaining normal height at conscription performed better in IP and PP compared with SGA males without catch-up growth. To our knowledge, there are no other studies in which the relation between catch-up growth in height and IP has been examined. In the present study, all SGA subgroups with catch-up growth scored better than those without, and the risk of subnormal performance was increased in those without catch-up growth.

The present study was large enough to permit powerful comparisons between different subgroups of SGA; each SGA subgroup contained more than 3000 infants. Birth data were collected prospectively, which precludes recall bias. The birth cohort studied was relatively homogeneous, consisting of nonmalformed male singletons born to Nordic mothers. Of the studied birth cohorts, $92 \%$ were conscripted. Test results on IP and PP were available for the vast majority of the conscripts (97\% for IP and $91 \%$ for PP). As military tests are considered military secrets, open information on validity and reliability of these tests is scarce. However, we have no reason to believe that possible misclassifications of the test results should differ with regard to birth characteristics. Neither do we suspect misclassifications in IP due to final height, as this test was entirely computer based.

Information about maternal factors, such as age, parity, smoking, socioeconomic status, and obstetrical and perinatal 
Table 3. Mean IP and PP for males born SGA in relation to birth characteristics and adult height. Adjusted OR and 95\% CI of subnormal IP and PP are also given

\begin{tabular}{|c|c|c|c|c|}
\hline \multirow[b]{3}{*}{ At birth } & \multicolumn{4}{|c|}{ Adult height } \\
\hline & \multicolumn{2}{|c|}{$>-2 \mathrm{SDS}$} & \multicolumn{2}{|c|}{$\leq-2 \mathrm{SDS}$} \\
\hline & Mean (SD) & OR $(95 \% \mathrm{CI})$ & Mean (SD) & OR $(95 \%$ CI) \\
\hline Short & $4.80(1.93)$ & $1.00 *$ & $4.30(1.92)$ & $1.45(1.21-1.70)$ \\
\hline Light & $4.71(1.90)$ & $1.11(0.99-1.22)$ & $4.15(1.95)$ & $1.89(1.58-2.20)$ \\
\hline Short and light & $4.58(1.89)$ & $1.18(1.06-1.30)$ & $3.99(1.88)$ & $2.01(1.79-2.23)$ \\
\hline Light & $4.83(1.79)$ & $0.98(0.85-1.10)$ & $4.34(1.68)$ & $1.43(1.07-1.79)$ \\
\hline Short and light & $4.72(1.77)$ & $1.11(0.98-1.24)$ & $4.19(1.70)$ & $1.74(1.49-1.98)$ \\
\hline
\end{tabular}

* Reference group, males born short for gestational age with adult height above -2 SDS.

Table 4. Birth characteristics for subgroups of SGA males and non-SGA males

\begin{tabular}{|c|c|c|c|c|}
\hline & \multicolumn{3}{|c|}{ SGA } & \multirow[b]{2}{*}{ Not SGA } \\
\hline & Short* & Light $\dagger$ & Short and light & \\
\hline Birth length, $\mathrm{cm}$ & $46.5(1.9)$ & $48.4(1.5)$ & $45.7(1.9)$ & $51.1(2.1)$ \\
\hline Birth weight, $g$ & $3002(380)$ & $2595(251)$ & $2425(363)$ & $3605(501)$ \\
\hline SDS & $-1.3(0.6)$ & $-2.4(0.3)$ & $-2.7(0.6)$ & $0.1(0.9)$ \\
\hline Head circumference, $\mathrm{cm}$ & $33.8(2.1)$ & $33.1(1.7)$ & $32.5(2.2)$ & $35.0(1.8)$ \\
\hline
\end{tabular}

Numbers given are mean (SD).

* Short for gestational age $(<-2$ SDS $)$.

$\dagger$ Light for gestational age $(<-2$ SDS $)$.

complications, was not included in analyses. SGA infants are at higher risk of asphyxia, which has been considered important as a predictor of cognitive deficits in previous studies $(3,5,8$, 23-27). Socioeconomic factors are known to influence final height and morbidity. Studies in Poland have demonstrated that, also within defined socioeconomic groups, those with tall adult stature had higher educational levels than those with short stature, suggesting that socioeconomic factors could not explain all of the associations $(28,29)$. Swedish society is rather homogenous, and existing socioeconomic differences are relatively small. Only males were included in the study, and as boys are reported to be more vulnerable than girls to intrauterine growth restriction, the interpretation of the findings should be restricted to boys (30).

In the present study, infants born SGA were classified into three subgroups - born short, born light, or born both short and light - as suggested by Albertsson-Wikland (18). Symmetrically (short and light) growth-restricted infants are considered to have a growth disturbance during the first trimester, and infants born asymmetrically growth restricted (light for gestational age) are considered to have a growth disturbance during the third trimester. The last group is regarded as less severely growth restricted and will more often have catch-up growth. It is believed that brain and skeletal growth are not affected by the restriction in infants born light $(31,32)$. Infants born only short-for-gestational-age are a less studied group. It could be hypothesized that these infants had a growth disturbance in the middle of gestation and thus are less severely growth restricted than those born short and light, but more severely growth restricted than those born light only. In the present study, those being born both short and light for gestational age (symmetric) had the lowest mean score in both tests. Symmetrical SGA infants (i.e. born both short and light), have often $(8,33)$, but not always (3), demonstrated less favorable neurodevelopmental outcome than infants born asymmetric. However, in the present investigation, SGA-born boys being both short and light were actually shorter than males classified as born short only, and lighter as a group than males born light only. The question was therefore raised whether the boys born both short and light constitute a specific subgroup, associated with increased risks, or whether these infants should be looked upon as just more severely growth restricted. When controlling for birth weight, birth length, and adult stature in multivariate analyses, males born both short and light were not associated with a further increased risk of subnormal IP and PP. The increased risk associated with being born both short and light is thus, to our understanding, just an additional effect to the risk of being short and the risk of being light.

A small head circumference was associated with an increased risk of low intellectual performance and slightly increased the risk of low PP in this study. A small head at birth has earlier been reported to be associated with low IP $(1,26)$ or minor neurologic dysfunction (5). A small head circumference measured shortly after birth may be due to reduced growth during pregnancy or due to compression during delivery. It is not possible to separate the importance of these factors based on our data.

There is ample literature showing increased neurodevelopmental risks in preterm infants, especially if they are SGA (3, $5,27,34)$. In the present study, preterm birth and SGA were 
independently associated with increased risk of subnormal performance in both the intellectual and the psychological tests.

Our data show that low birth weight for gestational age is associated with an increased risk of subnormal intellectual capacity in young adulthood. They are in accordance with most $(2,3,5,7,9,23,35)$, but not all $(25,36,37)$, previous studies. In contrast with previous studies, we also used birth length and catch-up growth as predictors. Independent of weight, we found that birth length is of importance for intellectual and psychological capacity, and lack of catch-up growth was associated with a substantially increased risk of subnormal performance in both the intellectual and psychological tests.

In conclusion, being short and/or light for gestational age is associated with increased risk of subnormal IP and PP. The data strongly support the view that it is an advantage to have catch-up growth in length for males born SGA.

Acknowledgments. The authors thank the National Service Administration of Sweden for making the data available. We also thank their chief psychologist, Johan Lothigius, National Service Administration of Sweden.

\section{REFERENCES}

1. Harvey D, Prince J, Bunton J, Parkinson C, Campbell S 1982 Abilities of children who were small-for-gestational-age babies. Pediatrics 69:296-300

2. Calame A, Fawer CL, Claeys V, Arrazola L, Ducret S, Jaunin L 1986 Neurodevelopmental outcome and school performance of very-low-birth-weight infants at 8 years of age. Eur J Pediatr 145:461-466

3. Tenovuo A, Kero P, Korvenrata H 1988 Developmental outcome of 519 small-for gestational age children at the age of two years. Neuropediatrics 19:41-45

4. Walther FJ 1988 Growth and development of term disproportionate small-forgestational age infants at the age of 7 years. Early Hum Dev 18:1-11

5. Hadders-Algra M, Huisjes HJ, Touwen BC 1988 Preterm or small-for-gestational-age infants. Neurological and behavioural development at the age of 6 years. Eur J Pediatr 147:460-467

6. Lagerström M, Bremme K, Eneroth P, Magnusson D 1991 School performance and IQ-test scores at age 13 as related to birth weight and gestational age. Scand J Psychol 32:316-324

7. Pryor J, Silva PA, Brook M 1995 Growth, development and behavior in adolescents born small-for-gestational-age. J Paediatr Child Health 31:403-407

8. Goldenberg RL, DuBard MB, Cliver SP, Nelson KG, Blankson K, Ramey SL, Herman A 1996 Pregnancy outcome and intelligence at age five years. Am J Obstet Gynecol 175:1511-1515

9. Strauss RS 2000 Adult functional outcome of those born small-for-gestational age: twenty-six-year follow-up of the 1970 British Birth Cohort. JAMA 283:625-632

10. Tanner JM 1986 Growth as a mirror of conditions of society: secular trends and class distinctions. In: Demirjam A, Brault Dubuc M (eds) Human Growth: A Multidisciplinary Review. London, Taylor and Francis

11. MacIntyre 1988 A review of the social patterning and significance or measures of height, weight, blood pressure and respiratory functions. Soc Sci Med 27:327-237
12. Allebeck P, Bergh C 1992 Height, body mass index and mortality: do social factors explain the association? Public Health 106:375-382

13. Tanner 1966 Galtonian eugenics and the study of growth. Eugenics Rev 58:122-135

14. Humphreys LG, Davey TC, Park RK 1985 Longitudinal correlation analysis of standing height and intelligence. Child Dev 56:1465-1478

15. Teasdale TW, Owen DR, Sörensen TIA 1991 Intelligence and educational level in adult males at the extremes of stature. Hum Biol 63:19-30

16. Tuvemo T, Jonsson B, Persson I 2000 Intellectual and physical performance and morbidity in relation to height in a cohort of 18-year-old Swedish conscripts. Horm Res 52:186-191

17. Leger J, Limoni C, Collin D, Czernichow P 1998 Prediction factors in the determination of final height in subjects born small for gestational age. Pediatr Res 43:808812

18. Albertssson-Wikland, Karlberg J 1994 Natural growth in children born small for gestational age with and without catch-up growth. Acta Paediatr Suppl 399:64-70

19. Tuvemo T, Cnattingius S, Jonsson B 1999 Prediction of male adult stature using anthropometric data at birth: a nationwide population-based study. Pediatr Res 46:491-495

20. Eriksson JG, Forsen T, Tuomilehto J, Winter PD, Osmond C, Barker DJ 1999 Catch-up growth and death from coronary heart disease: longitudinal study. BMJ 318:427-431

21. Cnattingius S, Ericson A, Gunnarskog J, Källén B 1990 A quality study of a medical birth registry. Scand J Soc Med 18:143-148

22. Niklasson A, Ericson A, Fryer JG, Karlberg J, Lawrence C, Karlberg P 1991 An update of the Swedish reference standards for weight, length and head circumference (1977-1981). Acta Paediatr Scand 80:756-762

23. Sørensen HT, Sabroe S, Olsen J, Rothman KJ, Gillman MW, Fischer P 1997 Birth weight and cognitive function in young adult life: historical cohort study. BMJ 315:401-403

24. Westwood M, Kramer MS, Munz D, Lovett JM, Watters GV 1983 Growth and development of full-term non-asphyxiated small-for-gestational-age newborns: follow-up through adolescence. Pediatrics 71:376-382

25. Fattal-Valevski A, Leitner Y, Kutai M, Tal-Posener E, Tomer A, Lieberman D, Jaffa A, Many A, Harel S 1999 Neurodevelopmental outcome in children with intrauterine growth restriction: a 3-year follow-up. J Child Neurol 14:724-727

26. Gross SJ, Kosmetatos N, Grimes CT, Williams ML 1978 Newborn head size and neurological status. Predictors of growth and development of low birth weight. Am J Dis Child 132:753-756

27. Martikainen M 1992 Effects of intrauterine growth retardation and its subtypes on the development of the preterm infant. Early Hum Dev 28:7-17

28. Bielicki T, Charzewski J 1983 Body height and upward social morbidity. Ann Hum Biol 5:403-408

29. Bielicki T, Waliszko H 1992 Stature, upward social mobility and the nature of statural differences between social class. Ann Hum Biol 19:589-593

30. Neligan GA, Kolvin I, Scott DM, Garside RF 1976 Born Too Soon or Born Too Small. A Follow-up Study to Seven Years of Age. Clinics in Developmental Medicine, No. 61. Heineman, London, pp 35-53

31. Prada JA 1998 Biological mechanisms or environmentally induced causes of IUGR. Eur J Clin Nutr 52(suppl 1):S21-S27

32. Wollmann HA 1998 Intrauterine growth restriction: definition and etiology. Horm Res $2: 1-6$

33. Villar J, Smeriglio V, Martorell R, Brown CH, Klein RE 1984 Heterogeneous growth and mental development of intrauterine growth-restricted infants during the first 3 years of life. Pediatrics 74:783-791

34. Matilainen R, Heinonen K, Siren-Tiusanen H 1988 Effect of intrauterine growth restriction (IUGR) on the psychological performance of preterm children at preschool age. J Child Psychol Psychiatry 29:601-609

35. Low JA, Handley-Derry MH, Burke SO, Peters RD, Pater EA, Killen HL, Berrick EJ 1992 Association of intrauterine fetal growth retardation and learning deficits at the age of 9 to 11 years. Am J Obstet Gynecol 167:1499-1505

36. Nilsen ST, Finne PH, Bergsjo P, Stamnes O 1984 Males with low birth weight examined at 18 years of age. Acta Paediatr Scand 73:168-175

37. Hawdon JM, Hey E, Kolvin I, Fundudis T 1990 Born too small—is the outcome still affected? Dev Med Child Neurol 32:943-953 